
\title{
$\begin{array}{ll}\text { Research Square } & \begin{array}{l}\text { Preprints are preliminary reports that have not undergone peer review. } \\ \text { They should not be considered conclusive, used to inform clinical practice, } \\ \text { or referenced by the media as validated information. }\end{array}\end{array}$
}

\section{The Efficacy of Baricitinib in Real-World Patients with Refractory or Severe Juvenile Dermatomyositis:A Monocentric Retrospective Study}

Zhaoling Wang

Zhejiang University School of Medicine Children's Hospital https://orcid.org/0000-0002-6645-1993

Qi Zheng

Zhejiang University School of Medicine Children's Hospital

XiSheng Xu

Zhejiang University School of Medicine Children's Hospital

Meiping Lu ( $\square$ meipinglu@zju.edu.cn )

The Children's Hospital of Zhejiang University School of Medicine https://orcid.org/0000-0002-4930-9493

\section{Research article}

Keywords: Juvenile dermatomyositis, Refractory, Baricitinib, Treatment.

Posted Date: January 10th, 2022

DOI: https://doi.org/10.21203/rs.3.rs-1226720/v1

License: (c) (i) This work is licensed under a Creative Commons Attribution 4.0 International License. Read Full License 


\section{Abstract \\ Objective}

To evaluate the efficacy and safety of low dose baricitinib in children with refractory or severe juvenile dermatomyositis (JDM) in a real-world setting

\section{Methods}

A monocentric retrospective real-world study was conducted, in which fourteen refractory and one severe newly diagnosed JDM patients were included. These patients were all treated by low dose baricitinib (below the recommended dose) combined with corticosteroids and or immunosuppressive agents. Clinical data were collected at the baseline and 4, 12, 24 weeks after baricitinib implication. Treatment response (complete response (CR), Partial response (PR) and non-response (NR)) was evaluated using both the Paediatric Rheumatology International Trials Organization (PRINTO) remission criteria and skin Disease Activity Score (DAS). All the adverse events (AEs) were recorded.

\section{Results}

After baricitinib treatment, all 15 patients showed improvement of skin involvement, including 14 patients with recurrent skin rashes and one newly diagnosed JDM. Calcinosis stabilized in two patients (2/3) and partially regressed in one. Four patients (4/15) had interstitial lung disease (ILD), which normalized in one, improved in two and stabilized in one. One patient complicated with macrophage activation syndrome (MAS) achieved clinical remission. CR was achieved in 3/15 patients, ranging from 4 to 12 weeks after baricitinib initiation. Five patients (5/15) got PR 4 to 24 weeks after baricitinib use. Daily steroid dosage was decreased from $0.632 \mathrm{mg} / \mathrm{kg}$ to $0.357 \mathrm{mg} / \mathrm{kg}(P=0.043)$ at 24 weeks in all responders. However, there was no statistically difference in muscle improvement. One patient was stopped using baricitinib because of varicella zoster virus infection, while no other serious side effect was observed in this study.

\section{Conclusion}

Low dose baricitinib had efficacy and was safe to applied in refractory or severe JDM patients, especially for recurrent skin rashes. Baricitinib may also be helpful for JDM complicated with ILD and MAS.

\section{Introduction}

Juvenile dermatomyositis (JDM) is an autoimmune disease characterized by inflammation of both the skin and muscles. Typical skin signs were Gottron papules, heliotrope rashes and nailfold capillary changes. Other organs may also be involved in JDM, including lungs, heart and gastrointestinal tract, leading to poor outcome of this disease. The pathogenesis of this disease is poorly understood which constraints targeted therapy drugs applying in JDM. Although the prognosis of JDM has been remarkably improved by corticosteroids (CS) combine with disease modifying antirheumatic drugs (DMARDs), there still have $20 \%$ patients who become refractory JDM or even unresponsive to the above therapy[1]. Other therapies such as intravenous immunoglobulin, rituximab, etanercept and adalimumab have yielded some promising results[2-5], but they are only beneficial in some of the refractory cases. Persistent skin lesions and calcinosis remain as the treatment challenge to rheumatologists. Recent studies have shown that interferons (IFNs) play a central role in the pathogenesis of both juvenile and adult dermatomyositis[6, 7]. Elevated IFN-response gene signature has been found in the blood, muscle and skin of dermatomyositis patients[8-10]. In treatment naive JDM patients, serum IFN-a activity was positively correlated with serum muscle enzymes[9]. Activation of IFNs results in reduction of myogenin expression and up-regulation of atrophy-associated genes[11]. Based on these findings, clinicians proposed IFN pathway inhibition as a mechanism based treatment for dermatomyositis. Janus kinase(JAK)-signal transducer and activator of transcription (STAT) pathway plays a key role in cytokine transduces signals, JAK inhibitors undergo competitive ATP binding to interfere and downregulate type I and II cytokine signaling, including IFNs signal. Actually, JAK inhibitors, such as tofacitinib, ruxolitinib and baricitinib had been reported to be used in JDM patients[12-20],which has shown efficacy in skin lesions, muscle weakness and amyopathic dermatomyositis-associated interstitial lung disease[12]. However, data on use of bairicitinib in JDM is limited[16], the efficacy and safety are still unclear. Here we reported a series of refractory and new-onset severe JDM patient who had received baricitinib to evaluate its efficacy and safety in a real-world setting.

\section{Methods}

\section{Patients}

We retrospectively reviewed 16 cases with JDM who received baricitinib between July 2019 and July 2021. All patients were from Children's Hospital of Zhejiang University School of Medicine. Fourteen refractory and one new-onset severe patients were included. One patient was excluded because of short course ( less than 4 weeks) of medication using, since the patient developed MAS with extremely high glutathione transaminase (647 IU) in the process of disease. The average age at disease onset of JDM was 8 years old. The female to male ratio was $3: 1$. The mean time to initiate baricitinib therapy was 22.87 months (range from 0 to 84 months) after diagnosis (Table 1). We collected the patients' clinical data at the baseline and 4,12 , and 24 weeks after baricitinib implication. Informed consents were obtained from parents before using baricitinib. The cost of medication was paid by patients themselves without supporting from company or other funding. Informed consents for publication were obtained from parents as well as subjects age over 14 years. The study was approved by the Ethics Committee of Children's Hospital of Zhejiang University School of Medicine (IRB approval no. 2019-IRB-154).

Page $2 / 10$ 
Inclusion criteria were: (i) diagnosis of JDM, according to the Bohan and Peter classification[21]; (ii) all patients with JDM received baricitinib; (iii) follow-up at least 6 months after the initiation of baricitinib. Exclusion criteria: (i) myositis overlapping with other autoimmune diseases; (ii) evidence of any other acute or chronic infectious diseases, history of tuberculosis or mycobacterial infections; (iii) history of any malignancy of any organ system; (iiii) baricitinib treatment course less than 4 weeks.

Refractory JDM was defined by active disease despite a 12 weeks of steroids and with or without one other first line immunosuppressive agents (e.g. methotrexate, mycophenolate mofetil, or azathioprine) or have demonstrated significant toxicity or intolerance to above therapies[22]. The diagnosis of ILD was made according to European protocols for the diagnosis of interstitial lung disease in children [23]. Macrophage activation syndrome (MAS) was diagnosed based on EULAR/ACR 2016 Classification Criteria[24]. Severe JDM was defined as disease progressed rapidly and/or involved other organs, including the lungs, heart, and gastrointestinal tract, leading to a poor prognosis. Low dose baricitinib was defined as below the recommended dose which based on weight and renal function[25].

\section{Efficacy evaluation of baricitinib in JDM}

Muscle strength was assessed using the Childhood Myositis Assessment Scale (CMAS, range 0-52) and the Manual Muscle Testing (MMT) scale (range 0-80). Severe muscle involvement was defined by CMAS score $\leq 15$ or MMT score $\leq 30$. Skin disease activity using the skin DAS (range $0-9$ ). Complete Response (CR) was defined by both the PRINTO criteria (at least three of the four following criteria have to be met: creatine kinase $\leq 150 \mathrm{U} / \mathrm{L}, \mathrm{CMAS} \geq 48$, MMT $\geq 78$, and Physician visual analogue scale (VAS) $\leq 2 \mathrm{~cm}$ (range, $1-10 \mathrm{~cm}$ ) and inactive skin DAS (score $\leq 1 / 9$ without cutaneous ulcerations or erythema). Partial response (PR) was defined as an improvement of the muscle and/or skin score assessed by MMT/CMAS and skin DAS, respectively, allow tapering of steroids dosage of at least $50 \%$ of the initial dosage at 6 months after baricitinib introduction, without adding a new immunosuppressive medicine. The outcome was counted as proportion of patients achieving CR/PR during 24 weeks after baricitinib implication. Stabilization or improvement in calcinosis was assessed by $\mathrm{X}$ ray and clinical manifestations.

\section{Adverse events}

Occurrence of adverse events (AEs) and serious AEs (SAEs) were monitored and reported in a standardized manner using the Common Terminology Criteria Adverse Events version 4.0.

\section{Statistical analysis}

Statistical analyses were performed using IBM SPSS statistics 25. Data from week 4, week 12 and week 24 were compared with baseline using Wilcoxon ranksum test.The continuous variables were presented as the medians with interquartile range (IQR) or mean with Standard deviation (SD). The categorical variables were presented as the number of patients and percentages.

\section{Results}

\section{The clinical features of JDM patients before baricitinib therapy}

All 15 patients had skin involvement, in which 14 patients had recurrent skin rashes and 3 patients had calcinosis. One patient was diagnosed as clinically amyopathic dermatomyositis (CADM). The median (IQR) skin DAS score was $6.00(5.00,7.75)$ before baricitinib therapy (Table 1$)$. Six of 15 patients had muscle involvement at the entry. Median (IQR) CMAS score or median (IQR) MMT score were $50.00(41.75,2.00)$ or 78.00 (73.25, 80.00), respectively. Two patients had severe muscle weakness who had CMAS score $\leq 15$ (Table 1). Four patients had interstitial lung disease (ILD), and one patients developed MAS in early stage of disease. The median dosage of corticosteroid at entry point of the study was $0.73 \mathrm{mg} / \mathrm{kg} / \mathrm{day}$.

\subsection{Bariticinib treatment of refractory or severe JDM}

As shown in Table 2, the enrolled patients received baricitinib at a dose of 1-2 mg once or twice daily. In addition to treatment with baricitinib, patients also received CS ( $n=12)$, intravenous methylprednisolone (IVMP, $n=3)$, intravenous immune globulin (IVIG, $n=8)$ and/or other biologic agent at the same time (Table 1). The duration of baricitinib treatment was from 3 months to 22 months (Table 2). The median duration of follow-up was 15.7 months (range from 6 to 22 months, Table2). Baricitinib was discontinued in one patient (P2) because of insufficient efficacy.

\subsection{Baricitinib had efficacy in children with refractory or severe JDM}

CR was achieved in 3/15 patients during 4 to 12 weeks after baricitinib initiation, it was sustained after a median duration of follow-up of 15.7 months. $5 / 15$ patients met PR ranging from 4 to 24 weeks. Eight patients were classified as non-responders (NR) within 24 weeks of observation. All responders ( $\mathrm{n}=8$, CR/PR) with a median (IQR) skin DAS score of 6.00 (5.00-7.75) at study entry were improved to $1.00(0.00,5.50)$ by 24 weeks $(P=0.001)$. The median (IQR) CMAS score of all enrolled patients was $50.00(41.75,52.00)$, which is indicative of only very mild muscle weakness at study entry. One patient had a CMAS score of $<15$ at entry who demonstrated 15-point improvement at 4 weeks. Calcinosis stabilized in two patients (P2, P12) and partially regressed in one (P3). ILD normalized in one of four (P9) patients, improved in two (P4, P14) and stabilized in one ( P5). One MAS was cured after baricitinib combined with IVMP, IVIG, tocilizumab and baricitinib.

\subsection{Baricitinib was helpful for tapering steroids and/or immunosuppressive agents dosage}

The daily steroid dose decreased from a median dosage of $0.632 \mathrm{mg} / \mathrm{kg} / \mathrm{day}$ at baricitinib introduction (range $0.227-1.000$ ) to $0.357 \mathrm{mg} / \mathrm{kg} / \mathrm{day}$ (range $0.224-0.500, P=0.043)$ at 24 weeks in all responders. Four (50\%) of the 8 responders were able to taper or remove immunosuppressive medication during 24 


\subsection{Baricitinib was overall well-tolerated and safe}

There were twenty AEs occurred in six patients in this study (Table 3). One patient who had herpes zoster infection required hospitalization and discontinuation of baricitinib temporarily.

\section{Discussion}

There has been increasing evidence documenting the critical role of type I IFNs in the development of JDM. Baricitinib, a JAK1/JAK2 inhibitor, interfering with I IFNs expression or signaling have already shown favourable results with baricitinib in refractory or sever newly JDM[16, 17, 26].

In this study, patients with cutaneous manifestations were improved markedly after baricitinib therapy. Significant improvement was noted at week 4 in skin $\mathrm{DAS}(\mathrm{P}=0.008)$. It was consistent with previous cases report that indicated baricitinib was clinically beneficial to skin lesions[16, 17, 26]. A case serials reported that 4 refractory JDM with baricitinib also showed skin disease improvement by week 4 [16]. Voyer and his colleague reported a new-onset case with severe skin ulcerations got CR after 1.7 months of baricitinib initiation [14]. Calcification is a therapeutic challenge in JDM. Data was limited in the treatment of JAKi in calcification, one paper displayed that only partially regressed was observed in a case who had JDM complicated with calcification[27, 28]. In our study, only partially regressed in one (1/3) patient with calcification in this study. Baricitinib may show good efficacy in the treatment of calcification if expanded the observation duration.

Previous study showed JAK inhibitor can restore muscle strength, significant improvement was observed after short usage[14, 29, 30]. In our study, one patient with severe muscle weakness was improved markedly (CMAS 15 to 30) upon baricitinib at 4 weeks of treatment. However, possible reason was that most patients enrolled in this study had mild muscle involvement.

JDM patients with ILD are often refractory to therapy. It was found that patients with anti-MDA5 antibodies positive were more prone to develop ILD[12, 28, $31-33][34,35]$. Four patients with ILD in our series had different MSAs (Table 1), an anti-PL-7-positive patient showed complete remission in images under the treatment of baricitinib. However, small size of our cohort makes it hard to distinguish which type of MSAs is an indication for the use of baricitinib.

It is reported that interference with IFN a/ $\beta$ expression or signaling following JAK/STAT inhibition may control catastrophic hyperinflammation in MAS[36, 37]. With comprehensive treatment that including IVMP, IVIG, tocilizumab and baricitinib, one patient effectively tackle the cytokine storm to get disease remission, which showed the possibility of baricitinib treatment of MAS in the real world.

Consistent with previous study, bariticinib maybe helpful for tapering the dose of steroid and other immunosuppressive medicine. In some case reports, JAK inhibitor may be beneficial when used alone[20]. In this study, daily corticosteroids were decreased from $0.632 \mathrm{mg} / \mathrm{kg} / \mathrm{day}$ at the entry of study, to $0.357 \mathrm{mg} / \mathrm{kg} /$ day $(\mathrm{P}=0.043)$. Half of these patients were able to reduce or remove other immunosuppressive medications.

Due to high price and off-label drug use, patients received dose of baricitinib from $1 \mathrm{mg}$ to $4 \mathrm{mg}$ per day, which is lower than other studies[16, 38]. It was costeffective to get response in $8 / 15$ patients during 6 months usage in this study. While, the non- response or PR in many patients might be due to this underdosing, that's one of our limitations in this study.

Bariticinib was reported as well-tolerated and safe in previous study[16, 29]. In our study, the most common AE was mild respiratory infection (Table 3). One patient infected with herpes zoster had to temporarily suspended using of Bariticinib. BK virus infection was often occurred in patients who receive immunosppressants or renal transplantation, while due to the lack of detection method and the absence of clinical manifestations of kidney disease in our patients, we did not routinely detect this virus.

Our study has another limitation as a single-centre study with small sample size and short observation period. It was carried out in a routine clinical practice situation, the effects of basic and combined medications may influence the truly efficacy of bariticinib. In addition, we did not measure the concentration of interferon-a protein made it unable to assess changes of in interferon expression in a molecular level.

\section{Conclusion}

This research indicated that low dose of baricitinib combined with immunosuppressants or biologics had efficacy in refractory or severe patients with JDM, especially in recurrent skin rashes. Bariticinib maybe helpful for tapering the dose of steroid and other immunosuppressive medicine. There was no serious side effects observed in this study, except for varicella zoster virus infection occurred in one patient. More cases and multicentre clinical trials are needed to identify the precise therapeutic effect in JDM .

\section{Abbreviations}

JDM:Juvenile dermatomyositis; DMARDs:disease modifying antirheumatic drugs; IFNs:interferons; JAK:Janus kinase; STAT: signal transducer and activator of transcription; CMAS:Childhood Myositis Assessment Scale; MMT: Manual Muscle Testing;VAS:visual analogue scale ; AEs:adverse events; SAEs:serious;CR:Complete Response; PR:Partial response; NR:non-responders; IQR:interquartile range;SD: Standard deviation; ILD:interstitial lung disease; IVMP:intravenous methylprednisolone; IVIG:intravenous immune globulin; CS:corticosteroids; MSAs:Myositis specific autoantibodies; 


\section{Declarations}

\section{Ethics approval and consent to participate}

The study has obtained approval from the Clinical Research Ethics Committee of Children's Hospital, Zhejiang University School ofMedicine(IRB approval no. 2019-IRB-154).

\section{Consent for publication}

All patients and their parents provided written informed consent for their data to be used in analyses and reported.

\section{Availability of data and materials}

All data generated or analyzed during this study are included in this published article [and its supplementary information files].

Competing interests

The authors have no funding and conflicts of interest to disclose.

Funding

This work was supported by National Science Foundation of China. (No.82070027)

\section{Authors' contributions}

ZLW was responsible of the collection of clinical information, statistical analyses, figures, data interpretation and manuscript preparation. QZ was responsible for critical review of the statistical analyses and the manuscript. XSX was assist in collecting clinical information. MPL is the project leader of the study; she is involved in the conceptualization of the project, the study design and preparation of the manuscript. All authors read and approved the final manuscript.

\section{Acknowledgements}

We are grateful for all participating patients and their families.

\section{References}

1. Ruperto N, Pistorio A, Oliveira S, Zulian F, Cuttica R, Ravelli A, Fischbach M, Magnusson B, Sterba G, Avcin T et al: Prednisone versus prednisone plus ciclosporin versus prednisone plus methotrexate in new-onset juvenile dermatomyositis: a randomised trial.Lancet (London, England) 2016, 387(10019):671-678.

2. de Inocencio J, Enríquez-Merayo E, Casado R, González-Granado LI: Subcutaneous Immunoglobulin in Refractory Juvenile Dermatomyositis. In., vol. 137; 2016.

3. Rouster-Stevens KA, Ferguson L, Morgan G, Huang C, Pachman LM: Pilot study of etanercept in patients with refractory juvenile dermatomyositis. In., vol. 66; 2014: 783-787.

4. Wang C: Successful Treatment of Refractory Juvenile Dermatomyositis With Adalimumab. In., vol. 23; 2017: 174-175.

5. Oddis CV, Reed AM, Aggarwal R, Rider LG, Ascherman DP, Levesque MC, Barohn RJ, Feldman BM, Harris-Love MO, Koontz DC et al: Rituximab in the treatment of refractory adult and juvenile dermatomyositis and. Arthritis and rheumatism 2013, 65(2):314-324.

6. Jiang J, Zhao M, Chang C, Wu H, Lu Q: Type I Interferons in the Pathogenesis and Treatment of Autoimmune Diseases. CLIN REV ALLERG IMMU 2020, 59(2):248-272

7. Kim H, Gunter-Rahman F, McGrath JA, Lee E, de Jesus AA, Targoff IN, Huang Y, O'Hanlon TP, Tsai WL, Gadina M et al: Expression of interferon-regulated genes in juvenile dermatomyositis versus. ARTHRITIS RES THER 2020, 22(1):69.

8. Moneta GM, Pires Marafon D, Marasco E, Rosina S, Verardo M, Fiorillo C, Minetti C, Bracci-Laudiero L, Ravelli A, De Benedetti F et al: Muscle Expression of Type I and Type II Interferons Is Increased in Juvenile Dermatomyositis and Related to Clinical and Histologic Features.Arthritis \& rheumatology (Hoboken, N.J.) 2019, 71(6):1011-1021

9. Kim H: Updates on interferon in juvenile dermatomyositis: pathogenesis and therapy.CURR OPIN RHEUMATOL 2021

10. Gitiaux C, Latroche C, Weiss-Gayet M, Rodero MP, Duffy D, Bader-Meunier B, Glorion C, Nusbaum P, Bodemer C, Mouchiroud G et al: Myogenic Progenitor Cells Exhibit Type I Interferon-Driven Proangiogenic Properties and Molecular Signature During Juvenile Dermatomyositis.Arthritis \& rheumatology (Hoboken, N.J.) 2018, 70(1):134-145.

11. Ladislau L, Suárez-Calvet X, Toquet S, Landon-Cardinal O, Amelin D, Depp M, Rodero MP, Hathazi D, Duffy D, Bondet V et al: JAK inhibitor improves type I interferon induced damage: proof of concept in dermatomyositis.Brain : a journal of neurology 2018, 141(6):1609-1621.

12. Sabbagh S, Almeida de Jesus A, Hwang S, Kuehn HS, Kim H, Jung L, Carrasco R, Rosenzweig S, Goldbach-Mansky R, Rider LG: Treatment of anti-MDA5 autoantibody-positive juvenile dermatomyositis using tofacitinib. Brain : a journal of neurology 2019, 142(11):e59.

13. Quintana-Ortega C, Remesal A, Ruiz de Valbuena M, de la Serna O, Laplaza-González M, Álvarez-Rojas E, Udaondo C, Alcobendas R, Murias S: Fatal outcome of anti-MDA5 juvenile dermatomyositis in a paediatric COVID-19 patient: a case report. In., vol. 5; 2021: 101-107. 
14. Voyer TL, Gitiaux C, Authier F, Bodemer C, Melki I, Quartier P, Aeschlimann F, Isapof A, Herbeuval JP, Bondet V et al: JAK inhibitors are effective in a subset of patients with juvenile dermatomyositis. Rheumatology (Oxford, England) 2021.

15. Heinen A, Schnabel A, Brück N, Smitka M, Wolf C, Lucas N, Dollinger S, Hahn G, Günther C, Berner R et al: Interferon signature guiding therapeutic decision making: ruxolitinib as first-line. Rheumatology (Oxford, England) 2021, 60(4):e136-e138.

16. Kim H, Dill S, O'Brien M, Vian L, Li X, Manukyan M, Jain M, Adeojo LW, George J, Perez M et al: Janus kinase (JAK) inhibition with baricitinib in refractory juvenile. In.; 2020.

17. Papadopoulou C, Hong Y, Omoyinmi E, Brogan PA, Eleftheriou D: Janus kinase 1/2 inhibition with baricitinib in the treatment of juvenile. In., vol. 142; 2019: e8.

18. Papadopoulou C, Hong Y, Omoyinmi E, Brogan PA, Eleftheriou D: Janus kinase 1/2 inhibition with baricitinib in the treatment of juvenile dermatomyositis. Brain : a journal of neurology 2019, 142(3):e8.

19. Aeschlimann FA, Frémond M, Duffy D, Rice GI, Charuel J, Bondet V, Saire E, Neven B, Bodemer C, Balu L et al: A child with severe juvenile dermatomyositis treated with ruxolitinib. In., vol. 141; 2018: e80.

20. Yu Z, Wang L, Quan M, Zhang T, Song H: Successful management with Janus kinase inhibitor tofacitinib in refractory juvenile. In., vol. 60; 2021: 17001707.

21. Lazarevic D, Pistorio A, Palmisani E, Miettunen P, Ravelli A, Pilkington C, Wulffraat NM, Malattia C, Garay SM, Hofer M et al: The PRINTO criteria for clinically inactive disease in juvenile dermatomyositis. In., vol. 72; 2013: 686-693.

22. Study of Tofacitinib in Refractory Dermatomyositis - Full Text View - ClinicalTrials.gov. In., vol. 2021: Study of Tofacitinib in Refractory Dermatomyositis Full Text View.

23. Bush A, Cunningham S, de Blic J, Barbato A, Clement A, Epaud R, Hengst M, Kiper N, Nicholson AG, Wetzke M et al: European protocols for the diagnosis and initial treatment of interstitial lung disease in children.THORAX 2015, 70(11):1078-1084.

24. Ravelli A, Minoia F, Davì S, Horne A, Bovis F, Pistorio A, Aricò M, Avcin T, Behrens EM, De Benedetti F et al: 2016 Classification Criteria for Macrophage Activation Syndrome Complicating Systemic Juvenile Idiopathic Arthritis: A European League Against Rheumatism/American College of Rheumatology/Paediatric Rheumatology Intemational Trials Organisation Collaborative Initiative. In., vol. 75; 2016: $481-489$.

25. Kim H, Brooks KM, Tang CC, Wakim P, Blake M, Brooks SR, Montealegre Sanchez GA, de Jesus AA, Huang Y, Tsai WL et al: Pharmacokinetics, Pharmacodynamics, and Proposed Dosing of the Oral JAK1 and JAK2 Inhibitor Baricitinib in Pediatric and Young Adult CANDLE and SAVI Patients.Clinical pharmacology and therapeutics 2018, 104(2):364-373.

26. Yeung T, Cheong K, Lau Y, Tse KN: Adolescent-onset anti-MDA5 antibody-positive juvenile dermatomyositis with rapidly progressive interstitial lung disease and spontaneous pneumomediastinum: a case report and literature review. Pediatric rheumatology online journal 2021, 19 (1):103.

27. Shneyderman M, Ahlawat S, Christopher-Stine L, Paik JJ: Calcinosis in refractory dermatomyositis improves with tofacitinib monotherapy: a. Rheumatology (Oxford, England) 2021.

28. Wendel S, Venhoff N, Frye BC, May AM, Agarwal P, Rizzi M, Voll RE, Thiel J: Successful treatment of extensive calcifications and acute pulmonary involvement in dermatomyositis with the Janus-Kinase inhibitor tofacitinib - A report of two cases. In., vol. 100; 2019: 131-136.

29. Paik JJ, Casciola-Rosen L, Shin JY, Albayda J, Tiniakou E, Leung DG, Gutierrez-Alamillo L, Perin J, Florea L, Antonescu C et al: Study of Tofacitinib in Refractory Dermatomyositis: An Open-Label Pilot Study of Ten Patients.Arthritis \& rheumatology (Hoboken, N.J.) 2021, 73(5):858-865.

30. Heinen A, Schnabel A, Brück N, Smitka M, Wolf C, Lucas N, Dollinger S, Hahn G, Günther C, Berner R et al: Interferon signature guiding therapeutic decision making: ruxolitinib as first-line therapy for severe juvenile dermatomyositis? Rheumatology (Oxford, England) 2021, 60(4):e136-e138.

31. Hosokawa Y, Oiwa H: A Case of Refractory Interstitial Lung Disease in Anti-MDA5-Positive Dermatomyositis. Journal of clinical rheumatology : practical reports on rheumatic \& musculoskeletal 2020.

32. Kurasawa K, Arai S, Namiki Y, Tanaka A, Takamura Y, Owada T, Arima M, Maezawa R: Tofacitinib for refractory interstitial lung diseases in anti-melanoma. Rheumatology (Oxford, England) 2018, 57(12):2114-2119.

33. Wu W, Guo L, Fu Y, Wang K, Zhang D, Xu W, Chen Z, Ye S: Interstitial Lung Disease in Anti-MDA5 Positive Dermatomyositis. CLIN REV ALLERG IMMU2021, 60(2):293-304

34. Takanashi S, Kaneko Y, Takeuchi T: Tofacitinib in interstitial lung disease complicated with anti-MDA5. MOD RHEUMATOL 2021:1-7.

35. Tansley SL, Betteridge ZE, Gunawardena H, Jacques TS, Owens CM, Pilkington C, Arnold K, Yasin S, Moraitis E, Wedderburn LR et al: Anti-MDA5 autoantibodies in juvenile dermatomyositis identify a distinct clinical phenotype: a prospective cohort study.ARTHRITIS RES THER 2014, 16 (4):R138.

36. Verweyen E, Holzinger D, Weinhage T, Hinze C, Wittkowski H, Pickkers P, Albeituni S, Verbist K, Nichols KE, Schulert G et al: Synergistic Signaling of TLR and IFNa/ $\beta$ Facilitates Escape of IL-18 Expression from. AM J RESP CRIT CARE 2020, 201(5):526-539.

37. La Rosée P: Alleviating the storm: ruxolitinib in HLH. In., vol. 127; 2016: 1626-1627.

38. Ohmura S, Yamabe T, Naniwa T: Successful dose escalation of tofacitinib for refractory dermatomyositis and. Modern rheumatology case reports 2021, 5(1):76-81.

\section{Tables}

Table1.Demographic and clinical characteristics of the 15 patients at baseline 


\begin{tabular}{|c|c|}
\hline \multicolumn{2}{|l|}{ Demographic characteristics } \\
\hline Age, mean $\pm S D$ years & $8.82 \pm 3.71$ \\
\hline Female sex-no.(\%) & $12(80)$ \\
\hline \multicolumn{2}{|l|}{ Clinical characteristics } \\
\hline Disease duration, median (IQR)months & $15.5(4.25,33.25)$ \\
\hline Corticosteroid usage at study entry-median (IQR)mg/kg/d & $0.73(0.37,1.03)$ \\
\hline Rash-no.(\%) & $15(100)$ \\
\hline Muscle weakness-no.(\%) & $6(40)$ \\
\hline calcification-no.(\%) & $3(20)$ \\
\hline ILD-no.(\%) & $4(26)$ \\
\hline MAS-no.(\%) & $1(6)$ \\
\hline MMT, median (IQR) score & $78.00(73.25,80.00)$ \\
\hline CMAS,median (IQR) score & $50.00(41.75,52.00)$ \\
\hline PGA,median (IQR) score & $5.00(5.00,7.00)$ \\
\hline Skin-DAS, median (IQR) score & $6.00 \rrbracket 5.00,7.75 \rrbracket$ \\
\hline Creatine kinase, median (IQR) IU/liter & $93.50(52.50,178.00)$ \\
\hline \multicolumn{2}{|l|}{ Myositis autoantibody-no.(\%) } \\
\hline NXP2 & $5(30)$ \\
\hline MDA5 & $2(12)$ \\
\hline TIF1Y & $2(12)$ \\
\hline PL-7 & $1(6)$ \\
\hline PL-12 & $1(6)$ \\
\hline SRP & $1(6)$ \\
\hline \multicolumn{2}{|l|}{ Prior treatment of refractory JDM"\#-no.(\%) } \\
\hline MTX & 13(92) \\
\hline HCQ & $8(57)$ \\
\hline CsA & $2(14)$ \\
\hline CTX & $2(14)$ \\
\hline FK506 & $2(4)$ \\
\hline LEF & $1(7)$ \\
\hline TGP & $1(7)$ \\
\hline MMF & $1(7)$ \\
\hline IVIG & $10(71)$ \\
\hline
\end{tabular}

\# Prior immunosuppressive treatments were not mutually exclusive, as patients may have been receiving more than one type of immunosuppressive agent at once prior to baricitinib. IQR;interquartile range;ILD:Interstitial lung disease;MAS Macrophage activation syndrome;CMAS: Childhood Myositis Assessment Scale; MMT: manual muscle testing;

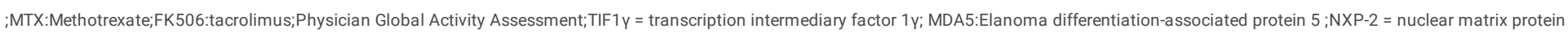

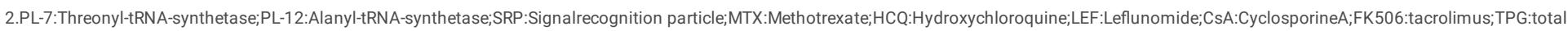
glucosides of paeonia;MMF:MycophenolateMofetil;CTX:Cyclophosphamide;IVIG:Intravenous immunoglobulin;IVMP:Intravenous methylprednisolone

Table 2. The characteristics, treatment and outcomes of each patient 


\begin{tabular}{|c|c|c|c|c|c|}
\hline Patient & $\begin{array}{l}\text { Ageat } \\
\text { diagnosisyears/sex }\end{array}$ & $\begin{array}{l}\text { Clinical involvement at } \\
\text { initiation of } \\
\text { Baricitinib,CMAS-14『MMT- } \\
\text { 8,skin-DAS }\end{array}$ & Treatment & SMAs/SAAs & $\begin{array}{l}\text { Dose of } \\
\text { Baricitinib,mg/kg }\end{array}$ \\
\hline P1 & $10 / \mathrm{F}$ & $52 / 52,80 / 80,8 / 9$ & $\mathrm{CS}^{\mathrm{a}} / \mathrm{TGP}^{\mathrm{c}} / \mathrm{MTX}^{\mathrm{a}} / \mathrm{HCQ}^{\mathrm{b}} /$ baricitinib & Negative & $2 \mathrm{mg} / 44.5 \mathrm{~kg}$ \\
\hline P2 & $11 / \mathrm{M}$ & $44 / 52,77 / 80,7 / 9$, calcinosis & $\mathrm{CS}^{\mathrm{d}} / \mathrm{MTX}^{\mathrm{d}} /$ Thalidomide$^{\mathrm{e}} / \mathrm{IVIG}^{\mathrm{C}} / \mathrm{INF} /$ baricitinib* & Negative & $2 \mathrm{mg} / 40.5 \mathrm{~kg}$ \\
\hline P3 & $8 / \mathrm{F}$ & $15 / 52,60 / 80,8 / 9$, calcinosis & $\mathrm{CS}^{\mathrm{a}} / \mathrm{LEF}^{\mathrm{b}} / \mathrm{MTX}^{\mathrm{d}} / \mathrm{HCQ}^{\mathrm{d}} /$ baricitinib/rhTNFR:Fc $\mathrm{C}^{\mathrm{b}} / \mathrm{IVIG}^{\mathrm{c}}$ & MDA5/Ro52 & $2 \mathrm{mg} / 41 \mathrm{~kg}$ \\
\hline P4 & $6 / F$ & $52 / 52,80 / 80,7 / 9$, ILD & $\mathrm{CS}^{\mathrm{a}} / \mathrm{MTX}^{\mathrm{b}} / \mathrm{CsA}^{\mathrm{b}} / \mathrm{b}$ aricitinib/HCQ$/ \mathrm{IVIG}^{\mathrm{c}}$ & MDA5/Ro52 & $1 \mathrm{mg} / 18 \mathrm{~kg}$ \\
\hline P5 & $10 / \mathrm{M}$ & $47 / 52,75 / 80,3 / 9$, ILD & $\mathrm{CS}^{\mathrm{a}} / \mathrm{MTX}^{\mathrm{b}} / \mathrm{HCQ}^{\mathrm{e}} /$ baricitinib/IVIG & NXP2 & $2 \mathrm{mg} / 55 \mathrm{~kg}$ \\
\hline P6 & $11 / \mathrm{M}$ & $29 / 52,61 / 80,8 / 9$ & $\mathrm{IVMP}^{\mathrm{b}} / \mathrm{CS}^{\mathrm{a}} / \mathrm{MTX}^{\mathrm{d}} / \mathrm{HCQ}^{\mathrm{d}} /$ baricitinib/IVIG & NXP2 & $2 \mathrm{mg} / 38 \mathrm{~kg}$ \\
\hline P7 & $2 / F$ & $50 / 52,74 / 80,5 / 9$ & IVMP $/ \mathrm{CS}^{\mathrm{c}} / \mathrm{MTX}^{\mathrm{d}} /$ baricitinib & NXP2 & $1 \mathrm{mg} / 25 \mathrm{~kg}$ \\
\hline P8 & $3 / \mathrm{M}$ & $52 / 52,80 / 80,5 / 9$ & $\mathrm{CS}^{\mathrm{a}} / \mathrm{MTX}^{\mathrm{d}} /$ baricitinib/IVIG ${ }^{\mathrm{C}}$ & TIF1Y & $1 \mathrm{mg} / 20.5 \mathrm{~kg}$ \\
\hline P9 & $10 / F$ & $41 / 52,73 / 80,8 / 9, I L D, M A S$ & $\mathrm{IVMP}^{\mathrm{c}} / \mathrm{CS}^{\mathrm{a}} / \mathrm{MTX}^{\mathrm{e}} / \mathrm{GsA}^{\mathrm{c}} /$ Tocilizumab$^{\mathrm{c}} /$ baricitinib/IVIGc & PL-12 & $1.5 \mathrm{mg} / 34 \mathrm{~kg}$ \\
\hline P10 & $1 / F$ & $52 / 52,80 / 80,6 / 9$ & IVMP ${ }^{b} / C^{a} / M_{T X}^{a} /$ baricitinib/IVIG & $\begin{array}{l}\text { SRP/PM- } \\
\text { SCl75 }\end{array}$ & $2 \mathrm{mg} / 12.5 \mathrm{~kg}$ \\
\hline P11 & $8 / F$ & $52 / 52,80 / 80,3 / 9$ & IVMP $/ \mathrm{CS}^{\mathrm{a}} / \mathrm{MTX}^{\mathrm{a}} /$ baricitinib/HCQ ${ }^{\mathrm{c}}$ & TIF1Y/Ro52 & $2 \mathrm{mg} / 28 \mathrm{~kg}$ \\
\hline $\mathrm{P} 12$ & $6 / F$ & $50 / 52,78 / 80,6 / 9$,calcinosis & $\mathrm{CS}^{\mathrm{d}} / \mathrm{CsA}^{\mathrm{b}} / \mathrm{CTX}^{\mathrm{b}} / \mathrm{rhTNFR} \mathrm{Fc}^{\mathrm{b}} /$ baricitinib/HCQ$/ \mathrm{IVIG}^{\mathrm{c}}$ & $\begin{array}{l}\text { NXP2/PM- } \\
\text { SCl75 }\end{array}$ & $4 \mathrm{mg} / 34 \mathrm{~kg}$ \\
\hline P13 & $10 / F$ & $49 / 52,78 / 80,3 / 9$ & IVMPb/CS ${ }^{\mathrm{a}} / \mathrm{MTX}^{\mathrm{d}} /$ baricitinib/FK506 $/$ IVIG $^{\mathrm{c}}$ & Negative & $1.5 \mathrm{mg} / 38.5 \mathrm{~kg}$ \\
\hline P14 & $14 / F$ & $52 / 52,80 / 80,6 / 9$, ILD & $\mathrm{CS}^{\mathrm{d}} / \mathrm{CTX} \mathrm{X}^{\mathrm{b}} / \mathrm{MMF}^{\mathrm{d}} /$ baricitinib/IVIG & PL-7 /Ro52 & $2 \mathrm{mg} / 47.5$ \\
\hline P15 & $9 / \mathrm{M}$ & $52 / 52,80 / 80,5 / 9$ & IVMPb/CS $/$ MTX $^{\mathrm{b}} / \mathrm{FK}^{\mathrm{b}} 56^{\mathrm{c}} /$ baricitinib/rhTNFR:Fc ${ }^{\mathrm{b}} / \mathrm{IVIG}^{\mathrm{c}}$ & NXP2 & $4 \mathrm{mg} / 44 \mathrm{~kg}$ \\
\hline
\end{tabular}

a Decrease the dose after baricitinib initiation.

b withdraw before baricitinib initiation

c withdraw after baricitinib initiation

d The dose of the drug remains the same

e additional or intensified use of other treatments

* baricitinib was withdrawn because of a muscle relapse at 24 weeks after the initiation

P:patient ;F: female ; M: male; CMAS: Childhood Myositis Assessment Scale; MMT: manual muscle testing; CR: complete responder; PR: partial responder;NR: non-responder;ILD:Interstitial lungdisease;CS:corticosteroid;MTX:Methotrexate;FK506:tacrolimus;JAKi:baricitinib;MMF:MycophenolateMofetil;

CTX:Cyclophosphamide;CsA:Cyclosporine A;IVIG:Intravenous immunoglobulin;IVMP:;HCQ:Hydroxychloroquine;SMAs:Myositis specific autoantibodies;MAA:Myositis associated antibodies;MDA5:Elanoma differentiation-associated protein 5 ;INF:Infliximabl

NXP2:Nuclear matrix protein 2 ;PL-7:Threonyl-tRNA-synthetase;TIF1y:Transcription intermediary factor 1

gamma;SRP:Signal recognition particle;

PL-12:Alanyl-tRNA-synthe

\section{Table 3 Adverse events}




\begin{tabular}{|ll|}
\hline All Events, $\mathrm{n}(\%)$ & \\
\hline Upper respiratory infection & $15(75 \%)$ \\
\hline Fungus infection & $1(5 \%)$ \\
\hline Gastrointestinal disorder & $1(5 \%)$ \\
\hline Herpes zoster & $1(5 \%)$ \\
\hline Elevation ofliver enzymes & $1(5 \%)$ \\
\hline Elevation of creatinine & $1(5 \%)$ \\
\hline
\end{tabular}

\section{Figures}

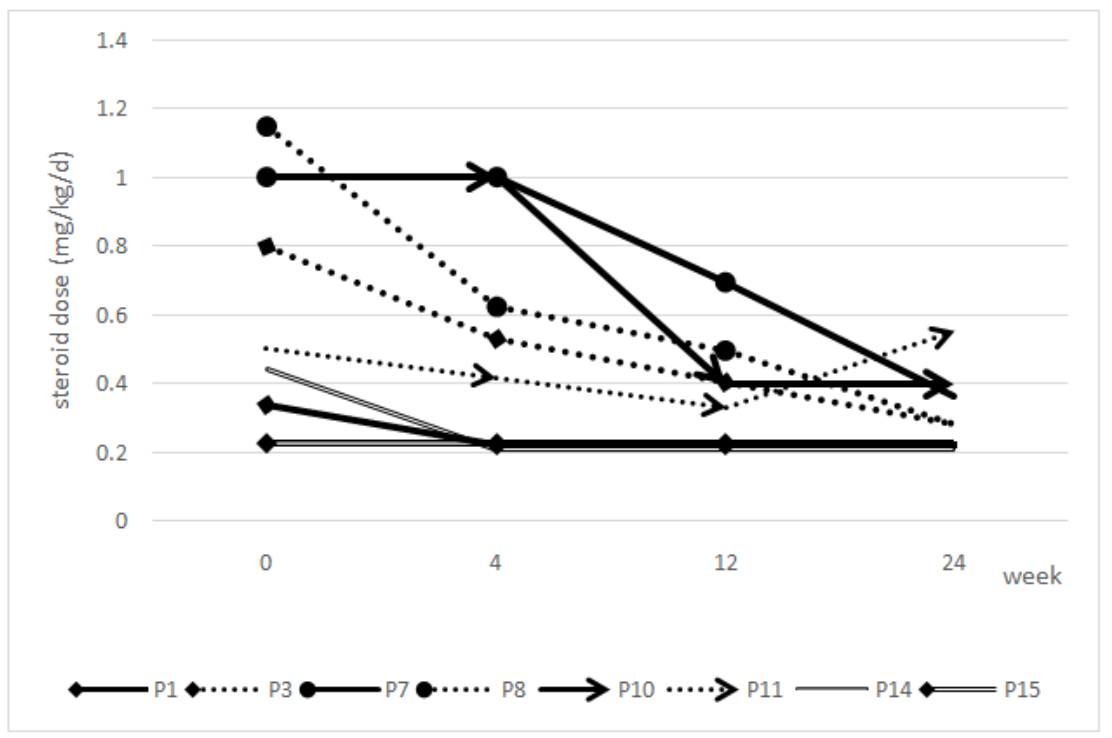

Figure 1

Caption not included with this version.

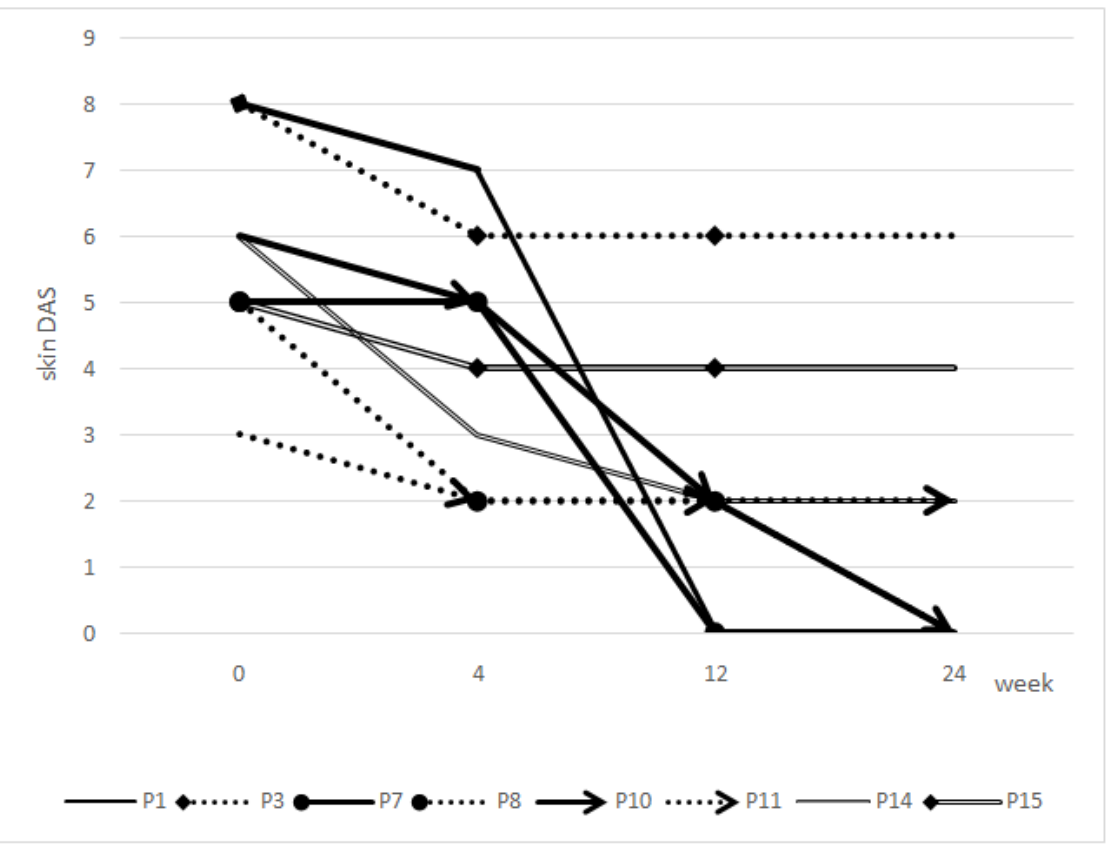

Figure 2 
Caption not included with this version.

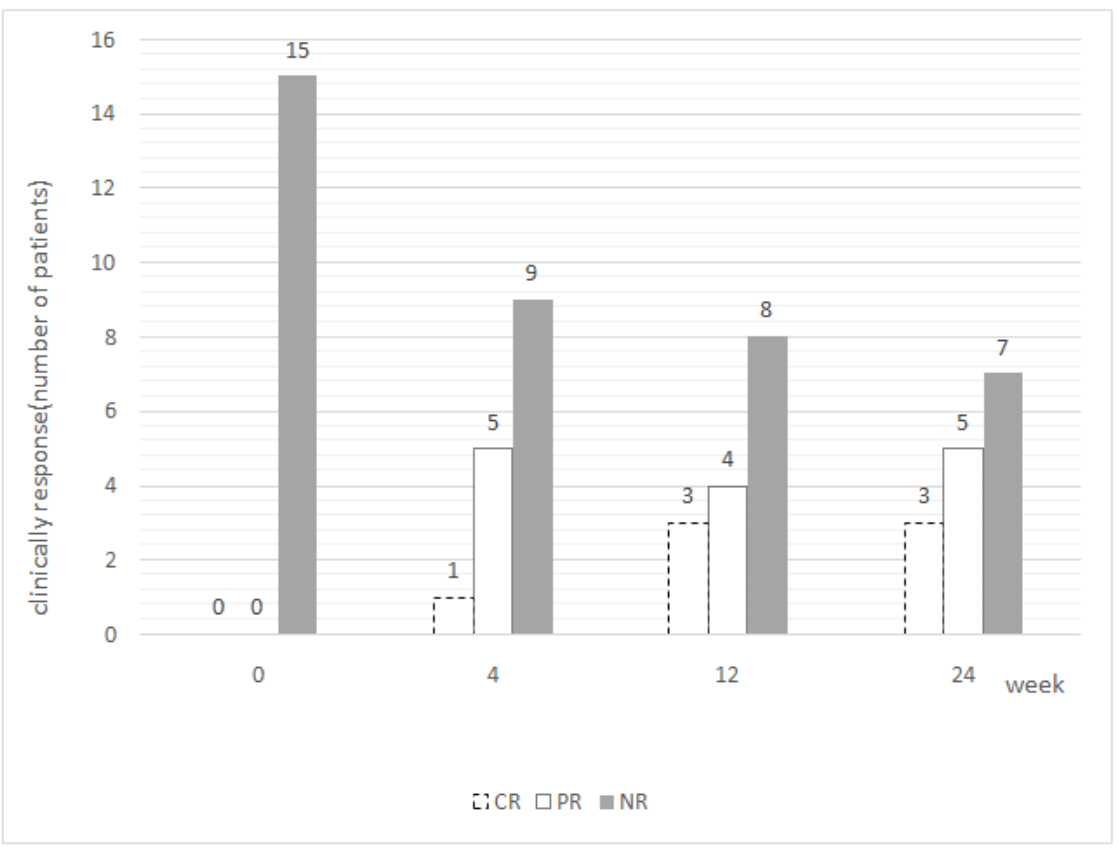

Figure 3

Caption not included with this version. 